\title{
Current review of Excimer laser Trabeculostomy
}

\author{
Georges M. Durr ${ }^{1,2^{*}}$, Marc Töteberg-Harms ${ }^{3}$, Richard Lewis ${ }^{4}$, Antonio Fea ${ }^{5}$, Paola Marolo ${ }^{5}$ and lqbal Ike K. Ahmed ${ }^{6}$
}

\begin{abstract}
Background: Excimer laser trabeculostomy (ELT) is a microinvasive glaucoma surgery (MIGS) that creates multiple laser channels through the trabecular meshwork using a cold laser system, which minimizes tissue fibrosis and aids in bypassing the main area of resistance to aqueous outflow. The purpose of this review is to evaluate the current body of evidence surrounding ELT in terms of efficacy and review the safety profile of the procedure.

Main text: Studies screened had to show clear inclusion and exclusion criteria as well as well-defined outcome measures. PubMed, MEDLINE, EMBASE and the Cochrane Controlled Trial Database were searched. Preferred Reporting Items of Systematic Reviews (PRISMA) guidelines were used to assess for study quality and for any bias. Sixty-four articles were initially identified with 18 meeting preliminary screening criteria. Ultimately, 8 studies met inclusion criteria and 2 additional non-referenced publications were also included: 1 randomized control trial, 4 prospective case series and 5 retrospective studies. Overall studies showed moderate intraocular pressure (IOP) lowering of between $20 \%$ and $40 \%$ from baseline without medication washout and mostly a decrease in glaucoma medications with few complications.

Conclusion: Current literature shows a significant IOP-lowering effect of ELT with a favorable safety-profile in standalone cases or combined with cataract surgery. Limitations to these studies are the lack of controls and washout IOP. Overall, ELT is an attractive MIGS option that does not require any residual device remaining in the angle.
\end{abstract}

Keywords: Excimer laser trabeculostomy, Trabeculotomy, ELT, Intraocular pressure, Glaucoma, MIGS, Cataract

\section{Background}

The glaucoma surgical landscape has significantly changed in recent years. The conventional treatment paradigm began with hypotensive drops, laser surgery and traditional filtering surgery such as tube shunts and trabeculectomies. Surgical practice patterns in the US now reflect an increase in microinvasive glaucoma surgery (MIGS) as an option for glaucoma management [1]. MIGS is an alternative to traditional glaucoma surgeries predicated on less invasive, more physiologic and less risky approaches

\footnotetext{
* Correspondence: georges.durr@gmail.com

'Department of Ophthalmology, Université de Montréal, Montreal, Quebec, Canada

2Department of Ophthalmology, Centre Hospitalier Universitaire de Montréal (CHUM), 1051 Rue Sanguinet, Montreal H2X 3E4, Quebec, Canada Full list of author information is available at the end of the article
}

to outflow enhancement. As evidenced by the Early Manifest Glaucoma Trial, nearly two thirds of patients initially present with early or moderate glaucoma [2]. As we move to a more interventional mindset for glaucoma care, mild to moderate disease may benefit from a less invasive procedure with modest intraocular pressure (IOP) lowering as this can aid in disease control, improve compliance or decrease eyedrop load.

MIGS aims to bypass the main area of conventional outflow resistance, the trabecular meshwork (TM), through stenting, dilating or cutting procedures. Aqueous humor travels through Schlemm's canal, traverses the TM and then drains through collector channels followed by aqueous veins and finally, episcleral veins to eventually enter the general circulation. Most aqueous veins are found in the inferior quadrants (more so in the infero-nasal quadrant), 
and there are generally two to three of these veins in a normal eye. Aqueous humor flow is believed to be controlled by a pump-like mechanism. The cardiac pulse, blinking and eye movements are thought to be the driving forces for transient oscillations in the collector system. The ability of Schlemm's canal to vary in volume and the TM to distend and recoil are characteristics of the outflow system that allow the pump to push aqueous downstream [3]. MIGS allows surgeons to tap into this mechanism and thereby treat the main area of resistance to outflow.

The chief hurdle for glaucoma procedures, including MIGS, is postoperative scarring, which often leads to a lack of long-term efficacy. What likely differentiates one MIGS procedure from the other is the ability to access the relevant distal outflow vessels, maintain the canal pump mechanism, and minimize postoperative healing and scarring.

Among the different options, excimer laser trabeculostomy (ELT; AIDA, Glautec AG, Nurnberg, Germany) was one of the first procedures to enter the MIGS surgical space with Berlin et al. initially proposing the concept of ELT in the late 1980s [4]. This predecessor device has been supplanted by the ExTra Laser System (MLase AG, Germering, Germany; ExTra ELT), which received a CE mark in 2014.

\section{What is ELT?}

ExTra ELT utilizes excimer laser technology to ablate portions of the TM and inner wall of Schlemm's canal. Excimer laser technology has been used for decades in refractive surgery because of its great precision, minimal thermal damage, very low tissue penetrance and non-lethality to adjacent cells. The photoablative properties of the laser breaks carbon-nitrogen and carbon-carbon tissue bonds with low energy $(4 \mathrm{eV})$ and does not transmit energy through water, which makes it an attractive option for intraocular use [5]. In refractive surgery, an excimer 193-nm laser is used. However, this wavelength is not transmissible through fiberoptics over a longer distance and can damage adjacent tissue if performed intracamerally $[4,6]$. To overcome the problem of being transmissible through fiberoptics, the ExTra Laser System uses a 308-nm xenon chloride (XeCl) excimer laser which creates $200-\mu \mathrm{m}$ trabeculostomy openings (laser channels) through the TM and inner wall of Schlemm's canal with an estimated treatment depth of $20 \mu \mathrm{m}$ (Fig. 1). The short pulse energy applied with Extra ELT is $1.2-1.3 \mathrm{~mJ}$ with a duration of $80 \mathrm{~ns}$. The quartz fiber-optic probe is powered by an excimer laser transmitting light to the TM for precise cold photoablation of the
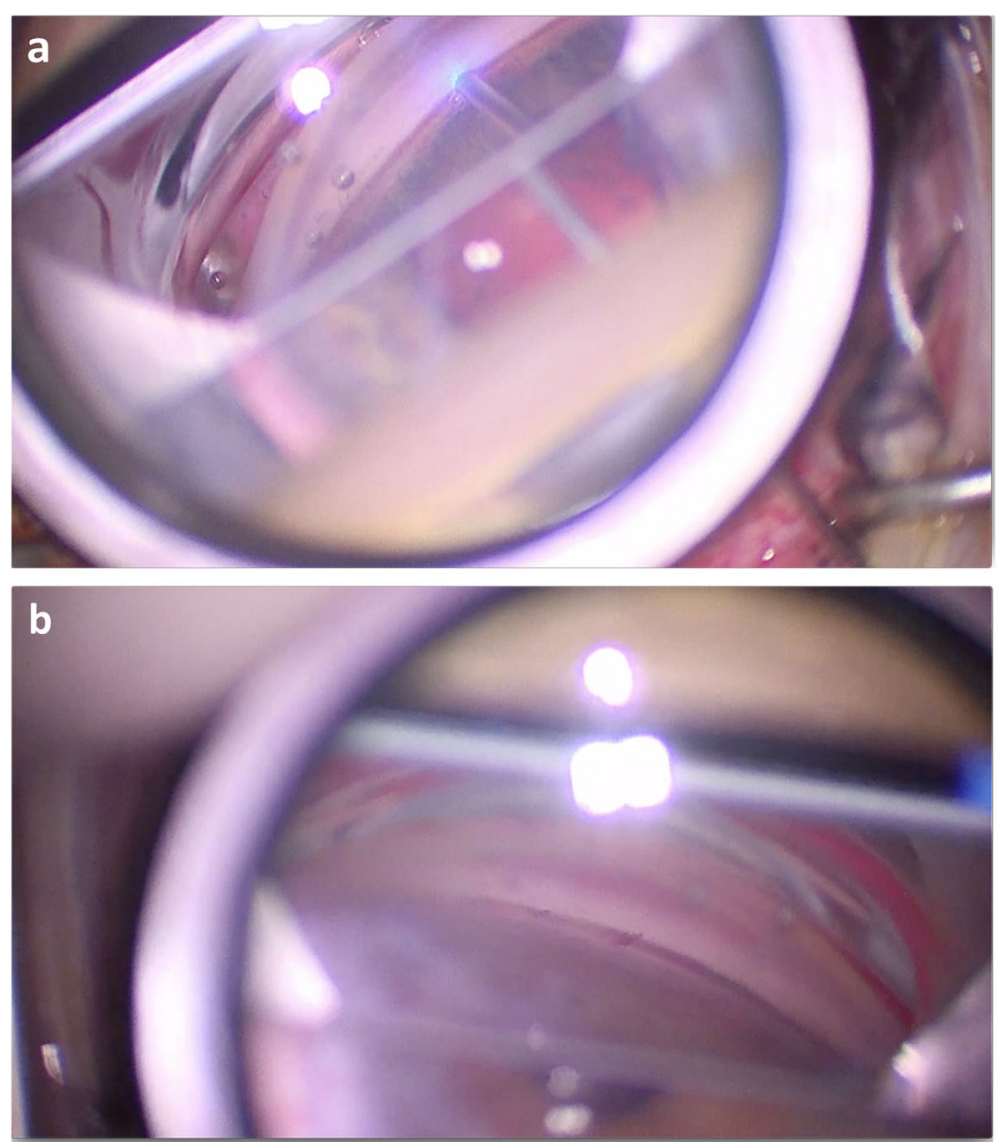

Fig. 1 Gonioscopic view of the Excimer Laser Trabeculostomy. View of the probe contacting the trabecular meshwork (a) and the subsequent trabeculostomy openings with bubble formation (b). Courtesy: Iqbal Ike K. Ahmed 
tissue, thereby obviating thermal damage [7]. An animal study on 10 rabbit eyes showed that trabecular cell mitochondria and endoplasmic reticula dilate initially as a result of the laser [8]. These cellular changes are transient and resolve spontaneously. A perhaps more compelling study finding was the absence of fibroblast migration up to 5 weeks after the procedure. This theoretically limits the amount of postoperative scarring.

\section{Surgical procedure}

The procedure can be performed standalone or combined with cataract surgery. When combined with phacoemulsification, ELT is typically performed following cataract extraction $(\mathrm{CE})$. The probe with an outer diameter of $500 \mu \mathrm{m}$ requires a $0.8 \mathrm{~mm}$ clear corneal incision. Under gonioscopic or endoscopic visualization, it is advanced bevel up, through the anterior chamber previously filled with viscoelastic and placed in direct contact with the TM. A foot pedal system is used to apply the laser energy. Usually, ten microchannels are created over 90 degrees, $500 \mu \mathrm{m}$ apart. Blood and microbubbles often seen after the laser is applied are likely the result of blood reflux from Schlemm's canal. One potential additional effect from the procedure is from the pneumatic canaloplasty $[4,9]$. As the photoablated tissue is transformed into gas, it has been hypothesized that these bubbles dilate Schlemm's canal, pushing the outer wall as well as adjacent collector channels.

After the procedure, patients are instructed to either stop all or continue some of their glaucoma medications as per surgeon preference. Typically, patients are started on combination antibiotic and steroid drops 3 or 4 times a day and tapered over 2-4 weeks.

\section{Why the renewed buzz around ELT?}

Around the time ELT was initially developing and being introduced into the clinical landscape, phacoemulsification was in the beginning stages of adoption, and few were approaching glaucoma therapy through an ab interno approach. At that time, argon laser trabeculoplasty and later, selective laser trabeculoplasty (SLT) were introduced using an incisionless approach with thermal energy to remodel the TM and allow for increased outflow. One drawback of these procedures is the creation of scar tissue as a result of thermal damage $[4,9]$. With the popularization of MIGS, multiple ab interno options are now commonly used in combination with cataract surgery or as standalone treatments. ELT returned to the treatment armamentarium with the arrival of a new CE-marked ExTra ELT laser platform in 2014 that is currently only available in the European Union. This platform has several potential advantages: it minimizes thermal damage, limits hyphemas and enables the creation of multiple implant-free microchannels through the TM. Ongoing clinical trials are anticipated to supplement the body of knowledge about this emerging device-free alterative for lowering IOP.

The purpose of this review is to summarize the current body of literature describing ELT and to provide an overview of the results from early experience with the device.

\section{Main text Methods}

This literature review was performed in accordance to the Preferred Reporting Items of Systematic Reviews (PRISMA) guidelines [10]. PubMed, MEDLINE, EMBASE and the Cochrane Controlled Trial Database and reference lists of original studies as well as reviews were searched. Keywords used in the search were 'excimer laser trabeculotomy' and 'excimer laser trabeculostomy'. Experts were contacted to identify unpublished trials. The date of the last search was September 4, 2019. No language restrictions were imposed.

Sixty-four articles were screened using a two-stage process. The first screening consisted of a review of titles and abstracts. Preliminary screening eliminated descriptive articles and general reviews that did not contain results of research studies on ELT. For those that passed the first stage, a reading of the full-text was performed. Any article written in a foreign language was translated by a medical translator into English.

The primary outcome of this review was to assess the current body of literature and the efficacy and safetyprofile of ELT.

\section{Data collection}

All studies selected included data describing baseline characteristics (age, sex, ethnicity), eye laterality, cup-to-disc ratio, glaucoma stage (mean deviation on visual field), follow-up time and technique variations. IOP measurements were the primary outcomes compared; means or medians, IOP at defined follow-up intervals and \% IOP reduction from baseline were compared. Success or failure criteria were also examined when available. Topical medication use, pre- and postoperatively, were also obtained. Studies were also screened for concomitant cataract surgery at the time of ELT. Intraoperative and postoperative complications and adverse events were also detailed and tallied.

\section{Results}

A total of 64 articles were identified by the literature review. Following initial assessment, 18 articles met the first screening criteria. Upon full text review, 8 articles were included in this review that had defined their methods, results and discussion [9, 11-17] (Table 1). Two additional non-referenced publications also were included in the review. 


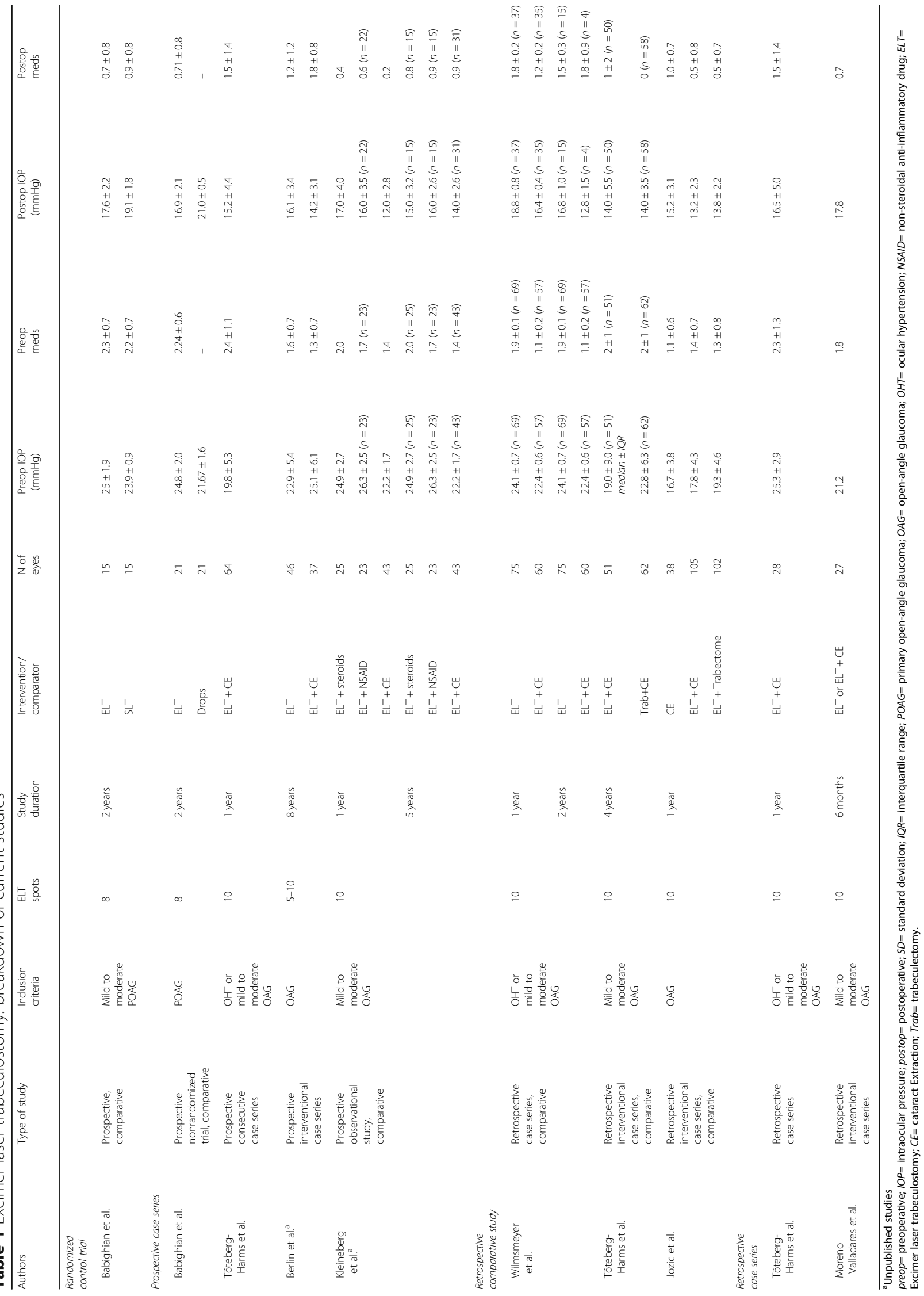




\section{Randomized control trial}

The highest level of evidence was provided by Babighian et al. with a single center randomized control trial in Italy comparing ELT $(n=15)$ with 180-degree SLT $(n=$ 15) over a 2-year follow-up in mild to moderate primary open angle glaucoma (POAG) [11]. All ELT and SLT were performed by the same operator ( 8 spots with ELT and 50 spots with SLT using $0.7-1.0 \mathrm{~mJ}$ of energy) and post-operative visits were performed by a masked physician. Complete success was defined as a $\geq 20 \%$ reduction in IOP without glaucoma medications (meds) and qualified success as $\geq 20 \%$ reduction in IOP with meds. Complete success was obtained for $53 \%(8 / 15)$ of ELT eyes compared to $40 \%(6 / 15)$ of SLT eyes ( $p=0.35$, Fisher's exact test). Regarding qualified success, $87 \%$ (13/15) of ELT eyes succeeded compared to $67 \%(10 / 15)$ of SLT eyes $(p=0.5$, Fisher's exact test). At 2 years, ELT decreased mean IOP from $25.0 \pm 1.9 \mathrm{mmHg}$ to $17.6 \pm 2.2$ $\mathrm{mmHg}(30 \%$ reduction; $p<0.0001)$ and SLT decreased mean IOP from $23.9 \pm 0.9 \mathrm{mmHg}$ to $19.1 \pm 1.8 \mathrm{mmHg}$ ( $21 \%$ reduction, $\mathrm{p}<0.0001$ ) with similar meds reduction compared to baseline [ELT: $2.3 \pm 0.7$ to $0.7 \pm 0.8$ ( $p=$ $0.005)$ vs SLT: $2.2 \pm 0.7$ to $0.9 \pm 0.8(\mathrm{p}<0.0001)]$. Complications included transient IOP spikes in both groups (3/15 with ELT and 2/15 with SLT) and mild reflux bleeding in 12/15 ELT eyes that resolved within 5 days.

\section{Prospective case series}

A prospective single-center case series by Babighian et al. examined results of ELT at 2-year follow-up in POAG with contralateral eye as a control [13]. ELT was performed over 90 degrees with 8 spots. Complete success was defined as $a \geq 20 \%$ reduction in IOP without any meds and qualified success as $\geq 20 \%$ reduction in IOP with meds. Mean IOP in the ELT group at baseline was $24.8 \pm 2.0 \mathrm{mmHg}$ and decreased to $16.9 \pm 2.1 \mathrm{mmHg}$ (32\% reduction, $p<0.0001$ ) at 2 years. Controls had no significant change to IOP at baseline $21.67 \pm 1.6 \mathrm{mmHg}$ and $21.0 \pm 0.5 \mathrm{mmHg}$ at 2 years. Complete success was obtained in $52 \%$ of eyes and qualified success in $90 \%$ of eyes. The only complications reported were small hyphemas in $80 \%$ of patients that spontaneously resolved within 5 days.

Töteberg-Harms et al. performed a 1-year prospective case series on 64 consecutive eyes undergoing combined $\mathrm{ELT}+\mathrm{CE}$ in patients with open angle glaucoma (OAG) [15]. ELT was performed over 90 degrees with 10 spots. Two groups were created based on preoperative IOP with group 1 having IOP $\leq 21 \mathrm{mmHg}$ and group 2 having IOP $>21 \mathrm{mmHg}$. Success was defined as IOP $\leq 21 \mathrm{mmHg}$ and $\geq 20 \%$ IOP reduction with same or less meds. Overall IOP dropped from $19.8 \pm 5.3 \mathrm{mmHg}$ to $15.2 \pm 4.4$ $\mathrm{mmHg}$ at 1 year (23\% reduction): group 1 IOP fell from $16.5 \pm 2.9 \mathrm{mmHg}$ to $14.6 \pm 3.7 \mathrm{mmHg}$ ( $12 \%$ reduction) and group 2 IOP from $25.8 \pm 2.9 \mathrm{mmHg}$ to $16.4 \pm 5.4$ $\mathrm{mmHg}$ (37\% reduction). Medication reduction was similar among groups (group 1: $2.5 \pm 1.0$ to $1.4 \pm 1.3$ at 1 year; group 2: $2.2 \pm 1.4$ to $1.6 \pm 1.5$ at 1 year). Overall success was obtained in $47 \%$ of the sample with a success rate of $38 \%$ in group 1 and $63 \%$ in group 2 . Seven patients (11\%) required further glaucoma surgery and a few patients had mild anterior chamber reaction. There was no mention of hyphema rates or IOP spikes.

\section{Retrospective comparative studies}

Lozic et al. reviewed a 1-year retrospective interventional case series comparing CE with ELT $+\mathrm{CE}$ and Trabectome (NeoMedix, Tustin, CA, USA) + CE in patients with OAG [17]. ELT was performed over 90 degrees with 10 spots and Trabectome was performed over 90 to 120 degrees. Mean IOP at baseline for the different groups were $16.7 \pm 3.8 \mathrm{mmHg}$ on $1.1 \pm 0.6$ meds (CE group, $n=38), \quad 17.8 \pm 4.3 \mathrm{mmHg}$ on $1.4 \pm 0.7$ meds $(\mathrm{ELT}+\mathrm{CE}$ group, $n=105)$ and $19.3 \pm 4.6 \mathrm{mmHg}$ on $1.3 \pm 0.8$ meds (Trabectome+CE group, $n=102$ ). At 1 year, mean IOP and meds dropped to $15.2 \pm 3.1 \mathrm{mmHg}$ on $1.0 \pm 0.7$ meds (CE group), $13.2 \pm 2.3 \mathrm{mmHg}$ on $0.5 \pm$ 0.8 meds (ELT $+\mathrm{CE}$ group) and $13.8 \pm 2.2 \mathrm{mmHg}$ on $0.5 \pm 0.7$ meds (Trabectome $+\mathrm{CE}$ group). Failure was defined as IOP $>21 \mathrm{mmHg}$ or $<20 \%$ IOP reduction or hypotony $(<5 \mathrm{mmHg})$ or loss of light perception vision. Kaplan-Meier curve showed improved mean survival time for the ELT + CE group (20.6 \pm 1.0 months) compared to the CE group (13.2 \pm 0.4 months) and the Trabectome $+C E$ group $(12.9 \pm 0.6$ months). There were no significant hyphemas or IOP spikes.

Töteberg-Harms et al. performed a 4-year retrospective interventional case series comparing ELT $+\mathrm{CE}$ and trabeculectomy (Trab) + CE in patients with OAG [16] ELT was performed over 90 degrees with 10 spots. Complete success was defined as IOP $\leq 21 \mathrm{mmHg}$ and $\geq$ $20 \%$ IOP reduction without meds and qualified success as IOP $\leq 21 \mathrm{mmHg}$ and $\geq 20 \%$ reduction in IOP with meds. IOP in the ELT + CE group $(n=51)$ at baseline was a median \pm interquartile range (IQR) of $19.0 \pm 9.0$ $\mathrm{mmHg}$ on $2 \pm 1$ meds; IOP decreased to $15.0 \pm 5.0$ $\mathrm{mmHg}$ on $1 \pm 2$ meds at 1 year and decreased further to $14.0 \pm 5.5 \mathrm{mmHg}$ on $1 \pm 2$ meds at 4 years. In comparison, baseline IOP in the Trab+CE group $(n=62)$ was $22.8 \pm 6.3 \mathrm{mmHg}$ on $2 \pm 1$ meds; IOP decreased to $13.0 \pm 4.5 \mathrm{mmHg}$ at 1 year on 0 meds and to $14.0 \pm 3.5$ $\mathrm{mmHg}$ on 0 meds at 4 years. Loss to follow-up was not reported. Complete success rate in the ELT + CE group was $18 \%$ at 1 year and $9 \%$ at 4 years; in the Trab+CE group, it was $90 \%$ at 1 year and $75 \%$ at 4 years. Qualified success rate in the ELT + CE group was $47 \%$ at 1 year and $34 \%$ at 4 years; in the Trab+CE group, it was $95 \%$ at 1 year and $89 \%$ at 4 years. Complications were reported 
as IOP spikes in $10 \%$ of the ELT + CE group and hypotony in $22 \%$ of $\mathrm{Trab}+\mathrm{CE}$ group. There was no mention of hyphema rates.

Wilmsmeyer et al. published a 2-year retrospective comparative case series in Germany of ELT $(n=75)$ and ELT combined with CE $(n=60)$ in OAG [12]. ELT was performed over 90 degrees with 10 spots. Success was defined as IOP $\leq 21 \mathrm{mmHg}$ and $\geq 20 \%$ IOP reduction (criteria 1 ) and as IOP $<18 \mathrm{mmHg}$ and $>30 \%$ IOP reduction (criteria 2). IOP for standalone ELT was $24.1 \pm$ $0.7 \mathrm{mmHg}$ at baseline $(n=69)$ followed by $18.8 \pm 0.4$ $\mathrm{mmHg}(n=66)$ at 3 months, $20.0 \pm 0.5(n=51)$ at 6 months, $18.8 \pm 0.8 \mathrm{mmHg}(n=37,22 \%$ reduction) at 12 months and $16.8 \pm 1.0 \mathrm{mmHg}(n=15,30 \%$ reduction) at 24 months $(p<0.001$ for all). Mean IOP for combined $\mathrm{ELT}+\mathrm{CE}$ was $22.4 \pm 0.6 \mathrm{mmHg}(n=57)$ at baseline, which decreased to $16.5 \pm 0.4 \mathrm{mmHg}(n=52)$ at 3 months, $16.1 \pm 0.5 \mathrm{mmHg}(n=40)$ at 6 months, $16.4 \pm$ $0.4 \mathrm{mmHg}(n=35,27 \%$ reduction $)$ at 12 months and $12.8 \pm 1.5 \mathrm{mmHg}(\mathrm{n}=4,47 \%$ reduction $)$ at 24 months $(p<0.01$ for all). Medications remained similar in the ELT and ELT + CE groups (ELT baseline: $1.9 \pm 0.1,12$ months: $1.8 \pm 0.2$ and 24 months: $1.5 \pm 0.3$; ELT $+\mathrm{CE}$ baseline: $1.1 \pm 0.2,12$ months: $1.2 \pm 0.2$ and 24 months: $1.8 \pm 0.9$ ). Success by criteria 1 was obtained in 46 and $66 \%$ at 12 months in the ELT and ELT + CE groups, respectively. Success by criteria 2 was obtained in 27 and $42 \%$ at 12 months in the ELT and ELT + CE groups, respectively. Complications were rare in this series: 2 patients had iris adhesions to the corneal tunnel, 3 had fibrinous anterior chamber reaction $(E L T+C E)$ and 1 patient had a central retinal vein occlusion, 5 months after the ELT $+C E$. There was no mention of hyphema rates or IOP spikes.

\section{Retrospective case series}

Töteberg-Harms et al. performed a 1-year retrospective case series in Switzerland on 24 consecutive eyes undergoing combined ELT + CE in patients with OAG [14]. ELT was performed over 90 degrees with 10 spots. Mean IOP at baseline was $25.3 \pm 2.9 \mathrm{mmHg}$ and decreased to $16.5 \pm 5.0 \mathrm{mmHg}$ at 1 year (IOP reduction $8.8 \pm 5.3$ $\mathrm{mmHg}, 37.7 \%$ ), and medications decreased from $2.3 \pm$ $1.3 \mathrm{mmHg}$ to $1.5 \pm 1.4 \mathrm{mmHg}$, respectively. Four patients required a secondary surgery due to uncontrolled IOP. There was no mention of hyphema rates or IOP spikes.

Moreno Valladares presented a 6-month retrospective interventional case series of his early experience in Spain of ELT and ELT + CE in 27 eyes with OAG [9]. Mean IOP in the ELT group was $21.2 \mathrm{mmHg}$ at baseline on 1.8 meds and decreased to $17.8 \mathrm{mmHg}$ on 0.7 meds at 6 months.

\section{Unpublished studies}

Two as yet unpublished studies are also noteworthy. Berlin et al. reported on 8-year results of a prospective nonrandomized trial with ELT $(n=46)$ and ELT + CE $(n=37)$ in patients with OAG [18]. Mean IOP decreased $29.7 \%$ from $22.9 \pm 5.4 \mathrm{mmHg}$ at baseline to $16.1 \pm 3.4$ $\mathrm{mmHg}$ at 8 years in the ELT group and fell $43.4 \%$ in the ELT + CE group from baseline $25.1 \pm 6.1 \mathrm{mmHg}$ on $1.3 \pm 0.7$ meds to $14.2 \pm 3.1 \mathrm{mmHg}$ on $1.8 \pm 0.8$ meds.

Kleineberg et al. performed a prospective, observational 60-month single-surgeon study in patients with OAG and no washout period, with three arms: ELT plus post-operative steroid drops (group $1, n=25$ ), ELT plus post-operative nonsteroidal anti-inflammatory drops (NSAIDs) (group 2, $n=23$ ) and ELT plus CE (group 3, $n=43$ ). ELT was performed with 10 spots. Mean preoperative medicated IOPs were $24.9 \pm 6.6 \mathrm{mmHg}, 26.3 \pm$ $5.8 \mathrm{mmHg}$ and $22.2 \pm 5.5 \mathrm{mmHg}$, respectively, and decreased at 1 year to $16.3 \pm 4.0 \mathrm{mmHg}, 15.7 \pm 3.5 \mathrm{mmHg}$ and $12.5 \pm 2.8 \mathrm{mmHg}$, respectively. At 60 months, mean IOPs were $15.5 \pm 3.2 \mathrm{mmHg}(n=15), 16.3 \pm 2.6 \mathrm{mmHg}$ $(n=15)$ and $14.1 \pm 2.6 \mathrm{mmHg}(n=32)$, i.e., decrements of $37.8,38$ and $36.5 \%$, respectively. Medications changed from 2.04 (baseline, $n=25)$ to 0.44 ( 1 year, $n=25)$ to 0.8 (5 years, $n=15$ ) for group 1 ; from 1.74 (baseline, $n=23$ ) to 0.59 ( 1 year, $n=23$ ) to 0.93 ( 5 years, $n=15$ ) for group 2; and from 1.40 (baseline, $n=43$ ) to 0.23 ( 1 year, $n=$ 43 ) to 0.94 ( 5 years, $n=31$ ) for group 3 . No hypotony was observed in any of the groups. Insufficient pressure reduction necessitated secondary surgical interventions in $3 / 91$ patients (3.3\%) with 1 patient from group 1 and 2 patients from group 3 . Only 3 patients had hyphema $>$ $1 \mathrm{~mm}$ and all were self-limited. Only 1 patient had an IOP spike of $\geq 10 \mathrm{mmHg}$, which resolved spontaneously by the next follow-up without any intervention. Visual acuity remained the same in groups 1 and 2 while it improved in group 3, which was mainly the result of the $\mathrm{CE}$.

\section{Discussion}

This review allows a comprehensive assessment of the current body of literature describing the use of ELT. All studies have shown moderate IOP lowering at variable time points, between 20 and $40 \%$ reduction from baseline without medication washout, and mostly a decrease in glaucoma medications with few complications [9, 11-18]. Although they are not direct comparisons, these results appear comparable or superior to those obtained with other MIGS [19].

Excimer lasers differ from frequency-doubling Yttrium Aluminum Garnet (YAG) lasers in several regards. $\mathrm{XeCl}$ lasers emit in the ultraviolet range $(308 \mathrm{~nm})$ in contrast to YAG lasers, which emit in the infrared range (1064 $\mathrm{nm})$. Tissue interactions differ following exposure to these divergent wavelengths. With ophthalmic Nd:YAG lasers, the protein-absorbed energy causes thermal coagulation, tissue shrinkage and tissue photodisruption by shock wave. It has been hypothesized that the $\mathrm{XeCl}$ laser 
directly and rapidly breaks protein bonds within cells whereas lasers in the infrared range can only indirectly re-shape tissue through photothermal and photomechanical changes to pigmented cells of the TM. Excimer lasers (excited dimer), using intense UV light, break molecular bonds and liberate molecular fragments while sparing adjacent tissues. One of the advantages of the excimer laser is the short depth of penetration of the laser $(30$ to $50 \mu \mathrm{m})$ [20]. Another differentiating concept is the formation of a plume with excimer lasers, which minimizes tissue damage. After the vapor bubble expands and collapses at the time of a pulse, a plume is created and carries away excess heat, effecting so-called cold ablation. Plumes are created when the laser pulse is shorter than the time required for heat to diffuse out of the irradiated zone. Excimer laser energy is not absorbed by liquids compared to higher wavelength lasers that rely on water absorption and result in higher collateral damage [21]. Considering the need to prevent postoperative healing and scarring to obtain long-term efficacy, the many unique characteristics of excimer lasers make it an attractive alternative for the creation of trabeculostomies.

Some studies have compared the effect of ELT as a standalone intervention or combined with cataract surgery $[12,18]$. There may be an additional benefit of combining ELT and cataract surgery as is believed to be the case in other MIGS procedures [22]. Cataract surgery may help potentiate the effect of ELT. The combined or synergistic effect of the two procedures has not yet been fully elucidated because these studies are limited by the lack of control arms. Cataract surgery has a well-documented albeit modest IOP-lowering effect, which may confound the ELT portion of the IOP decrease [23-26]. Ideally, a trial comparing cataract surgery alone or combined with ELT is warranted to better ascertain the additive or synergistic effect from the laser procedure. Another consistent finding was that higher preoperative IOP led to a better response to ELT [15]. This is often the case in most glaucoma trials. When the IOP is lower, achieving success becomes more challenging as a significant drop in IOP is much more difficult to achieve with lower preoperative pressures. Notably, none of the studies in this review used washout or decision IOP (IOP at the time the decision was made to proceed with surgery) values to obtain pre- or postoperative values, which potentially would have provided greater absolute and percent IOP reductions.

The best evidence to date is from an randomized control trial comparing ELT to 180-degree SLT [11]. This was a well-designed study with clear outcome measures and good follow-up, despite a small sample size. ELT appeared to outperform SLT although this was not statistically significant likely due to an underpowered study. Some limitations of this study arose from the study design. SLT was performed over 180 degrees. Arguably, there may be a difference in the treatment effect of 180 degrees compared to 360 degrees; however, some studies have shown equivalent IOP response between 180 and 360 degrees with fewer IOP spikes [27, 28]. Another question that this study raises is whether SLT is the best comparator. SLT is an incision-less procedure using thermal energy to reshape the TM by incompletely understood mechanisms to allow further outflow. Although ELT acts on TM through a cold laser system with less potential for damage, it does require an incision and thus carries a small increased risk of infection compared to SLT. No cases of endophthalmitis were reported in the studies described in this review. Furthermore, ELT must be performed in the operating room (OR) with increased preparation/surgical time compared to SLT, which is performed in the office. When combined with CE, ELT requires additional surgical time [15]. The use of an endoscope or intraoperative gonioscopy to visualize the angle is another potential limitation of the procedure. Surgical skill in the use of an endoscope or with intraoperative gonioscopy to visualize the angle is another potential limitation of the procedure.

Other comparators are trabecular bypass MIGS or trabeculotomies. The potential advantage of ELT over any trabecular bypass device is that ELT does not require any material to remain in the angle with the attendant potential risks of corneal decompensation or device migration. Compared to trabeculotomies, ELT spots are small $(200 \mu \mathrm{m})$ with lower potential risk of the severe hyphemas that have been reported with trabeculotomies [29-31]. Furthermore, excimer-created openings theoretically would be less likely to scar and/or close compared to traumatic tearing or cutting procedures in the TM. A single retrospective study compared ELT + CE to Trabectome $+\mathrm{CE}$ and showed comparable mean IOP and decreased medication use at 1-year [17]. The results for the ELT + CE group were superior to those of the other groups in terms of survival analysis although this finding may have been subject to bias related to nonrandomization or differential preoperative IOPs. To date, no headto-head prospective randomized study comparing standalone ELT to trabecular bypass MIGS or trabeculotomies has been conducted. One study compared ELT + $\mathrm{CE}$ with trabeculectomy $+\mathrm{CE}$ with the latter outperforming ELT + CE although the ELT + CE group had a faster recovery and a favorable safety profile (IOP spikes in $10 \%$ of the ELT $+\mathrm{CE}$ group; hypotony in $22 \%$ of Trab+CE group) [16]. The result is not surprising considering that blebs are expected to lower IOP more substantially than a canal-based procedure, which is limited (and protected) by episcleral venous resistance. Trabeculectomy, with both short- and long-term potential bleb complications (hypotony, infection, bleb leaks, choroidal 
detachments) is typically reserved for more advanced or uncontrolled glaucomas. Trabeculectomy remains the gold standard for glaucoma management worldwide. However, in view of the significant risks, patients and physicians are inclined to choose a bleb-less procedure with modest IOP response for mild or moderate glaucomatous disease. Such procedures are considered adequate to prevent future glaucoma damage by better controlling IOP, decreasing drop load and improving compliance.

Complications were rare in the studies reviewed, and the few reported were mainly due to hyphemas and IOP spikes. The transient perioperative hyphemas were small, unassociated with IOP spikes, did not require treatment and resolved within a few days. Intraoperatively, creation of the laser microchannels produces a small amount of hemorrhage into the anterior chamber, subsequently cleared with irrigation. In effect, this observation confirms the patency of the trabeculostomy and results from blood reflux. To date no study has reported a significant hyphema that lead to uncontrolled IOP or the need for an anterior chamber washout. IOP spikes have been reported in $10-15 \%$ of cases in 2 studies and all resolved without the need for further surgical intervention [11, 16]. IOP spikes in these settings may be due to pigment release, inflammation, blood or retained viscoelastic at the end of the procedure.

\section{Conclusions}

Overall, current available evidence show an IOP-lowering effect from ELT alone or in combination with cataract surgery with encouraging results across different studies and patient populations, notably without washout IOP, and a favorable safety profile. Multiple studies, albeit with small sample sizes and variable loss to follow-up, have shown a long-lasting response up to 8 years after the initial surgery. The potential advantages of this procedure are less scarring than results from traditional thermal lasers, repeatability in different quadrants, ease of use, no device left in the angle and, with lower hyphema risks compared to ablative procedures, potentially less secondary synechia to the angle. The procedure also appears to have a favorable safety profile with few intraoperative or postoperative risks. Like any new technology, more studies are needed to better characterize ELT and further substantiate these promising results.

\section{Acknowledgments}

Not applicable

\section{Authors' contributions}

GMD literature review and major contributor in writing the manuscript. PM created the tables and reviewed the manuscript. All authors read and approved the final manuscript.
Funding

Not applicable

Availability of data and materials

Data sharing is not applicable to this article as no datasets were generated or analyzed during the current study.

Ethics approval and consent to participate

Not applicable

Consent for publication

Not applicable

\section{Competing interests}

IIKA: Financial support - Consultant, ELT Sight.

MTH: Financial support - Consultant, ELT Sight \& EYELight.

AF: Financial support - Consultant, ELT Sight.

\section{Author details}

'Department of Ophthalmology, Université de Montréal, Montreal, Quebec Canada. ${ }^{2}$ Department of Ophthalmology, Centre Hospitalier Universitaire de Montréal (CHUM), 1051 Rue Sanguinet, Montreal H2X 3E4, Quebec, Canada.

${ }^{3}$ Department of Ophthalmology, University Hospital Zurich, Zurich, Switzerland. ${ }^{4}$ Sacramento Eye Consultants, Sacramento, California, USA.

${ }^{5}$ Struttura Complessa Oculistica, Città della Salute e della Scienza di Torino, Dipartimento di Scienze Chirurgiche, Università degli Studi di Torino, Torino, Italy. ${ }^{6}$ Department of Ophthalmology \& Vision Sciences, University of Toronto, Toronto, Ontario, Canada.

Received: 9 December 2019 Accepted: 13 April 2020

Published online: 05 May 2020

\section{References}

1. Vinod K, Gedde SJ, Feuer WJ, Panarelli JF, Chang TC, Chen PP, et al. Practice preferences for glaucoma surgery: a survey of the American Glaucoma Society. J Glaucoma. 2017;26(8):687-93.

2. Heijl A, Bengtsson B, Oskarsdottir SE. Prevalence and severity of undetected manifest glaucoma: results from the early manifest glaucoma trial screening. Ophthalmology. 2013;120(8):1541-5.

3. Schacknow PN, Samples JR. The Glaucoma Book - A Practical, EvidenceBased Approach to Patient Care. 1st ed. New York: Springer; 2010.

4. American Academy of Ophthalmology. Berlin MS, Toeteberg-Harms M, Kim E, Vuong I, Giers U. Excimer Laser Trabeculostomy: An Effective Microinvasive Glaucoma Surgery Procedure for Open-Angle Glaucoma. 2013. https://www.aao.org/munnerlyn-laser-surgery-center/excimer-lasertrabeculostomy-effective-microinvasi;: Accessed 19 Sept 2004.

5. Puliafito CA, Steinert RF, Deutsch TF, Hillenkamp F, Dehm EJ, Adler CM. Excimer laser ablation of the cornea and lens. Experimental studies. Ophthalmology. 1985;92(6):741-8.

6. Martinez M, Maguen E, Bardenstein D, Duffy M, Yoser S, Papaioannou T, et al. A comparison of excimer laser ( $308 \mathrm{~nm}$ ) ablation of the human lens nucleus in air and saline with a fiber optic delivery system. Refract Corneal Surg. 1992;8(5):368-74

7. Richter GM, Coleman AL. Minimally invasive glaucoma surgery: current status and future prospects. Clin Ophthalmol. 2016:10:189-206.

8. Huang S, Yu M, Feng G, Zhang P, Qiu C. Histopathological study of trabeculum after excimer laser trabeculectomy ab interno. Yan Ke Xue Bao. 2001;17(1):11-5

9. Moreno Valladares AM, Amorós NP, López FG. Excimer laser trabeculostomy: trabecular MIGS without implant. Revista Española de Glaucoma e Hipertensión Ocular. 2018;8(2):19-27.

10. Moher D, Liberati A, Tetzlaff J, Altman DG, Group TP. Preferred reporting items for systematic reviews and meta-analyses: The PRISMA Statement PLoS Med. 6:e1000097. https://doi.org/10.1371/journal.pmed.1000097.

11. Babighian S, Caretti L, Tavolato M, Cian R, Galan A. Excimer laser trabeculotomy vs 180 degrees selective laser trabeculoplasty in primary open-angle glaucoma. A 2-year randomized, controlled trial. Eye (Lond). 2010;24(4):632-8.

12. Wilmsmeyer $\mathrm{S}$, Philippin $H$, Funk J. Excimer laser trabeculotomy: a new, minimally invasive procedure for patients with glaucoma. Graefes Arch Clin Exp Ophthalmol. 2006;244(6):670-6. 
13. Babighian S, Rapizzi E, Galan A. Efficacy and safety of ab interno excimer laser trabeculotomy in primary open-angle glaucoma: two years of followup. Ophthalmologica. 2006;220(5):285-90.

14. Töteberg-Harms M, Ciechanowski PP, Hirn C, Funk J. One-year results after combined cataract surgery and excimer laser trabeculotomy for elevated intraocular pressure. Ophthalmologe. 2011;108(8):733-8.

15. Töteberg-Harms M, Hanson JV, Funk J. Cataract surgery combined with excimer laser trabeculotomy to lower intraocular pressure: effectiveness dependent on preoperative IOP. BMC Ophthalmol. 2013;13:24.

16. Töteberg-Harms M, Wachtl J, Schweier C, Funk J, Kniestedt C. Long-term efficacy of combined phacoemulsification plus trabeculectomy versus phacoemulsification plus excimer laser trabeculotomy. Klin Monatsbl Augenheilkd. 2017;234(4):457-63.

17. Jozic L, Magner J, Funk J, Töteberg-Harms M. Success of combined cataract extraction plus excimer laser trabeculotomy exceeds that of combined ab interno trabeculectomy with the trabectome or cataract extraction alone. Int Ophthalmol. 2020:40(3):529-37.

18. Berlin M, Töteberg-Harms M, Roka V, Kleineberg L, Stodtmeister R, Giers U, et al. Excimer Laser Trabeculostomy (ELT), a Laser Based MIGS Procedure with No Implants, Enables Consistent Intraocular Pressure-Lowering in Glaucoma Patients Over 8 Years, Both Stand-Alone and Combined With Phacoemulsification. In: 27th American Glaucoma Society Meeting; 2017.

19. Conlon R, Saheb H, Ahmed II. Glaucoma treatment trends: a review. Can J Ophthalmol. 2017;52(1):114-24.

20. Stamper RL, Lieberman MF, Drak MV. Becker-Shaffer's Diagnosis and Therapy of the Glaucoma. 8th ed. Maryland Heights: Mosby; 2009.

21. Dowding C. Advances in laser materials processing: Woodhead publishing; 2010

22. Singh K. Things go better with cataract surgery. Ophthalmology. 2014; 121(1):1.

23. Mansberger SL, Gordon MO, Jampel H, Bhorade A, Brandt JD, Wilson B, et al. Reduction in intraocular pressure after cataract extraction: the ocular hypertension treatment study. Ophthalmology. 2012;119(9):1826-31.

24. Vold S, Ahmed II, Craven ER, Mattox C, Stamper R, Packer M, et al. Two-year COMPASS trial results: supraciliary microstenting with phacoemulsification in patients with open-angle glaucoma and cataracts. Ophthalmology. 2016; 123(10):2103-12.

25. Samuelson TW, Sarkisian SR Jr, Lubeck DM, Stiles MC, Duh YJ, Romo EA, et al. Prospective, randomized, controlled pivotal trial of an ab interno implanted trabecular micro-bypass in primary open-angle glaucoma and cataract: two-year results. Ophthalmology. 2019;126(6):811-21.

26. Samuelson TW, Chang DF, Marquis R, Flowers B, Lim KS, Ahmed IIK, et al. A schlemm canal microstent for intraocular pressure reduction in primary open-angle glaucoma and cataract: the HORIZON study. Ophthalmology. 2019;126(1):29-37.

27. Cheema SA, McGlynn RH, George MK, Ford BA, Wand M, Martone JF, et al. Efficacy of 180 vs. 360 degrees of selective laser trabeculoplasty on lowering intraocular pressure. Invest Ophthalmol Vis Sci. 2006:47(13):5466.

28. Prasad N, Murthy S, Dagianis JJ, Latina MA. Comparison of the intervisit intraocular pressure fluctuation after 180 and 360 degrees of selective laser trabeculoplasty (SLT) as a primary therapy in primary open angle glaucoma and ocular hypertension. J Glaucoma. 2009;18(2):157-60.

29. Grover DS, Godfrey DG, Smith O, Shi W, Feuer WJ, Fellman RL. Outcomes of gonioscopy-assisted transluminal trabeculotomy (GATT) in eyes with prior incisional glaucoma surgery. J Glaucoma. 2017;26(1):41-5.

30. Dorairaj SK, Seibold LK, Radcliffe NM, Aref AA, Jimenez-Román J, LazcanoGomez GS, et al. 12-month outcomes of goniotomy performed using the Kahook Dual Blade combined with cataract surgery in eyes with medically treated glaucoma. Adv Ther. 2018;35(9):1460-9.

31. Minckler D, Mosaed S, Dustin L, Ms BF, Trabectome Study Group. Trabectome (trabeculectomy-internal approach): additional experience and extended follow-up. Trans Am Ophthalmol Soc. 2008;106:149-59; discussion $159-60$

\section{Ready to submit your research? Choose BMC and benefit from:}

- fast, convenient online submission

- thorough peer review by experienced researchers in your field

- rapid publication on acceptance

- support for research data, including large and complex data types

- gold Open Access which fosters wider collaboration and increased citations

- maximum visibility for your research: over $100 \mathrm{M}$ website views per year

At $\mathrm{BMC}$, research is always in progress.

Learn more biomedcentral.com/submissions 